\title{
Teleological organisation
}

\author{
Sune Holm ${ }^{1}$ John Basl ${ }^{2}$
}

Published online: 24 February 2017

(C) Springer Science+Business Media Dordrecht 2017

We are very pleased to introduce this special issue of Synthese on Teleological Organization. The topic of Teleological Organization is extraordinarily intersubdisciplinary. Work in this area, we think you'll find, highlights the rich connections between diverse areas of philosophy, creating a common area of interests for those working in the philosophy of science, especially the philosophy of biology, ecology, and neurophysiology, those working in value theory including metaethics, normative ethics, applied ethics, and axiology, and those working in philosophy of mind and language. This issue highlights some of that common ground, but more importantly makes progress on issues of interest to those working in these areas.

One reason for the intersubdisciplinarity in issues of teleological organization is the role that teleological organization has come to play in various areas of value theory where notions of teleology have been used to clarify and understand notions of wellbeing and the structure of attributions of goodness. It is unsurprising, given this, that these areas of value theory would draw from or depend upon work in the philosophy of science where issues of teleology have been front and center in debates about the nature of function ascriptions.

These connections are most evident in three contributions to this issue. In "Nothing in ethics makes sense except in the light of evolution? Natural goodness, normativity, and naturalism" Jay Odenbaugh argues that proponents of natural goodness approaches - those that believe that attributions of goodness to natural entities share a similar structure to attributions of moral goodness to humans-face serious challenges

$凶 \quad$ Sune Holm

suneh@hum.ku.dk

1 Philosophy Section, Department of Media, Cognition and Communication,

University of Copenhagen, Copenhagen, Denmark

2 Department of Philosophy, Northeastern University, Boston, USA 
when we take seriously the account of natural functions, the etiological or selectedeffects theory of function, that is best suited to ground claims of natural teleology and try to apply that in any serious way to make ethical judgments. In "A Trilemma for Teleological Individualism” John Basl argues that Teleological Individualists, those who claim that individual organisms are teleologically organized while ecosystems and other biological collectives are not, have typically endorsed an etiological account of teleology to make good on their view but have paid insufficient attention to the issues of the levels of selection. He argues that there is no view about the levels of selection that is sufficient to do the work that Teleological Individualists claim and so, at best, those that depend on such a view, including many working in environmental ethics, must find some new way to defend their commitments to Teleological Individualism.

If anything, the above papers seem to undermine the common ground between philosophy of science and biology and value theory. However, a third paper seeks to offer new foundations for collaboration. In "Teleology and Biocentrism" Sune Holm argues that Biocentrists, those that have seemed most dependent on natural teleology to make good on their views about the welfare of non-sentient life, should adopt an alternative to etiological or selected-effect theories of teleology. These accounts he argues, despite their virtues, fail to appropriately accommodate plausible views about which sorts of things, such as synthetic organisms have a welfare. Instead, he explores how adopting more recent organizational accounts of teleology might solve various problems and create new space for Biocentrists to defend their views.

The organizational account of teleology suggested by Holm as a solution to certain problems at the connection between ethics and biology is developed, in detail, in another contribution to this issue. In "What Makes Biological Organization Teleological?" Matteo Mossio and Leonardo Bich argue that we can understand teleology as arising from self-determining systems, systems whose activity contributes to the conditions of that systems existence. The central challenge with such an account is to articulate the conditions for self-determination such that not every biological system or system with response-dependent mechanism counts as teleological. Mossio and Bich aim to identify the sorts of causal relationships between components of an organized biological system that makes it count as self-determining in the relevant sense.

The papers so far mentioned highlight disputes about the relationship of functions to teleology and what that means for various issues outside the functions literature. Two other papers in this issue show why debates about functions are still relevant to philosophy of science. In "A Persistence Enhancing Propensity Account of Ecological Function to Explain Ecosystem Evolution" Antoine Dussault and Frederic Bouchard argue for an extension of causal-role accounts of function, specifically those that are forward-looking such as Bigelow and Pargetter's fitness enhancing account, can be extended to capture function ascriptions in ecology. While accounts of biological function have typically been designed to capture the functional organization of organisms, Dussault and Bouchard argue that not only can such an account accommodate functional organization at the ecosystemic-level but that doing so helps to reconcile ecology and evolutionary biology, providing us a mechanism for thinking about the functional organization and evolution of ecosystems.

In "Functional Analysis and Species Design" Karen Neander extends on the important work she has done on functions over the last several decades. In particular she 
takes issue with the apparently well-established consensus amongst function theorists that functional biologists such as physiologists and neurophysiologists appeal to Cummins functions in explaining the workings of bodies and brains. Neander argues that function theorists should not rest assured that Cummins functions are superior to selected functions as candidates for answering How-questions. Her central claim is that what she characterises as normal-proper functions of system components are of explanatory significance in functional biology. Still, such normal-proper functions are neither Cummins functions, nor are they causally efficacious properties of their bearers. Thus, Neander concludes that selected functions as characterised by the etiological theory are good candidates for being normal-proper functions and may thus serve the explanatory needs of functional biologists.

One of the main selling points of the etiological theory of functions defended by Neander is that it promises to provide a non-intentional basis for accounting for the teleological nature of biological functions. The final paper of the issue takes up a recent objection to the etiological theory of function. According to the circularity objection, there is no coherent, non-circular way to determine whether two trait tokens are of the same trait type. In the final paper of the issue, "Two Arguments for the Etiological Theory over the Modal Theory of Biological Function”, Brain Leahy and Maximilian Huber defend the etiological theory against this objection in part by providing arguing that homology is an adequate way of individuating trait types.

Acknowledgements This special issue is in part the result of a workshop on teleological organisation held at the Carlsberg Academy in Copenhagen August 2012. We would like to thank the Danish Council for Independent Research for their financial support for the workshop. Also thanks to the contributors and to Otávio Bueno for his support as the editor-in-chief taking care of this issue. 